\title{
Incidence of fimbriated strains amongst haemolytic Escherichia coli
}

\author{
Prem Singh Grover ${ }^{1}$, Rajesh Bareja ${ }^{2}$, Vinod Kumar Narang ${ }^{3}$, Subash Chand \\ Jaryal $^{4}$ \\ 1,2,3 (Department of Microbiology, M.M.I.M.S.R, Mullana, Ambala, Haryana, India - 133207) \\ ${ }^{4}$ (Department of Microbiology, R.P. Medical College, Tanda, Himachal Pradesh, India-176001)
}

\begin{abstract}
A total of 23,007 clinical samples, 2,001 were identified as Escherichia coli (E.coli). Among these, 205 strains were haemolytic. One hundred eighty one E.coli were found haemolytic among urinary isolates. Two tests i.e. salt aggregation test (SAT) and haemagglutination test (HAT) with human type A erythrocytes were performed to know the incidence of fimbriated strains amongst haemolytic E.coli isolates. Mannose resistant haemagglutination and Mannose sensitive haemagglutination was observed in 95 (46.34\%) and 15 (7.31\%) strains respectively. Whereas cell surface hydrophobicity was shown by 139 (67.80\%) strains. Seventy nine (38.53\%) strains were both SAT and HAT positive. Twenty nine (14.14\%) strains were both SAT and HAT negative i.e. non-fimbriated strains. Among urinary isolates, $21.8 \%$ were found to possess both haemolytic and haemagglutinating activity. Haemolytic activity of E.coli was found associated with fimbriated strains. Thus, both act as virulence factors for the pathogenesis of Urinary Tract Infection.
\end{abstract}

Keywords: Cell surface hydrophobicity; Fimbriae; Haemolytic Escherichia coli; Haemagglutination

\section{Introduction}

The virulence of E.coli is multifactorial. Bacterial adherence is an essential virulence factor in the pathogenesis of community acquired urinary tract infections [1-3]. The fimbria has been described as a microbial surface component that mediates specific attachment to eukaryotic cell membrane [4]. Fimbrial mediated adherence has been proposed as an important virulence factor in the development of urinary tract infection. Adherence of pyelonephritic E.coli has been correlated with their ability to cause a D-mannose resistant haemagglutination of human erythrocytes [5]. The property of hydrophobicity has also been attributed to fimbriae. Hydrophobic interactions are thought to be involved in the adhesion of bacteria to mucus surface by formation of hydrophobic bonds [6].

Haemolytic E.coli are more likely to cause disease than non-haemolytic E.coli [7]. There is paucity of reports in the correlation of the existence of fimbriae and the haemolytic character of E.coli. So it was planned to study the incidence of haemolytic E.coli isolates in various clinical samples and to determine the presence of fimbriae on the strains.

\section{Material And Methods}

The study was carried out in a tertiary care hospital over a period of twenty months. During the study, 23007 clinical samples were received in the department of Microbiology for culture and sensitivity. All the samples were inoculated on the MacConkey agar and Blood agar by standard methods and incubated at $37^{\circ} \mathrm{C}$ overnight [8]. The haemolytic E.coli were identified on the basis of colony morphology and confirmed by biochemical characters [9]. A total of 205 strains of haemolytic E.coli thus isolated were stored in soft agar at $4^{\circ} \mathrm{C}$ till studied. The presence of fimbriae was demonstrated by HAT and SAT. E.coli (H-10407) strain was used as positive control.

Haemagglutination test (HAT): It was performed by the method of Siegfried et al., (1994). Bacteria were inoculated into $5.0 \mathrm{ml}$ of Muellar-Hinton broth and incubated at $37^{\circ} \mathrm{C}$ until pellicle was formed. An inoculum was taken from the pellicle, inoculated on to CFA agar and incubated at $37^{\circ} \mathrm{C}$ for 18 hours [11]. Five colonies of the growth on CFA agar were picked and suspended in $1.0 \mathrm{ml}$ of phosphate buffered saline (PBS pH 7.3). Fifty microliter of bacterial suspension was mixed with equal volume of erythrocytes suspension (Human type A, 3\% $\mathrm{v} / \mathrm{v}$ in PBS) at two places on a clean glass slide. To one drop of the mixture, 50 $\mu 1$ of PBS was added and to the other drop, 50 $\mu$ l of D-mannose (3\% v/v in PBS) was added, mixed, gently rotated for one minute and examined for the presence of agglutination of erythrocytes. Positive control was also set up with E.coli H-10407. The results were interpreted as follows:

1. The test strain was labeled as mannose resistant haemagglutination (MRHA) if the haemagglutination was observed both, in the mixture containing D-mannose and mixture without D-mannose.

2. The strain was labeled as mannose sensitive haemagglutination (MSHA) if the agglutination was inhibited in 
mixture containing D-mannose and agglutination was present in the mixture without D-mannose.

3. Report of no haemagglutination was assigned where there was no agglutination in either of the mixture.

Salt aggregation test (SAT): Cell surface hydrophobicity was measured by salt aggregation test [10]. All the strains were grown on CFA agar plates at $37^{\circ} \mathrm{C}$ for 18 hours to enhance the production of fimbrial antigens. The bacterial suspensions $\left(5 \times 10^{9} \mathrm{cfu} / \mathrm{ml}\right)$ were prepared in $0.2 \mathrm{M}$ phosphate buffer $(\mathrm{pH} 6.8)$. The suspension is mixed with ammonium sulphate solution at final molar concentration of 2.0, 1.4, 1.0, 0.4, 0.06 and 0.02 on a clean glass slide, gently rotated and examined for aggregation of bacteria. The strains were considered hydrophobic when they aggregated in ammonium sulphate solution at concentration $\leq 1.4 \mathrm{M}$. To compare the results, the positive control (E.coli $\mathrm{H}-10407)$ was also set up simultaneously.

\section{Results}

Out of 23,007 clinical samples, 6,209 bacterial isolates were obtained. Of these 6,209 isolates, 2,001 were identified as E.coli. Among these E.coli isolates, 205 were found to be haemolytic. Haemagglutination was shown by 110 strains. MRHA and MSHA were observed in $95(46.34 \%)$ and $15(7.31 \%)$ strains respectively by HAT (Fig. 1). No haemagglutination (MRHA, MSHA) was observed in 95 (46.34\%) strains (Table 1). One hundred thirty nine $(67.81 \%)$ strains were found to be hydrophobic by SAT (Table 2). In the present study, out of 205 haemolytic strains of E.coli, 29 (14.14\%) were both SAT and HAT, negative. Seventy nine (38.53\%) of the total strains were both SAT and HAT positive. Out of 95 MRHA and 15 MSHA E.coli, 19 (20\%) and 5 $(33.3 \%)$ were salt aggregation test negative. Whereas 184 strains were found to be SAT, positive and HAT, negative.

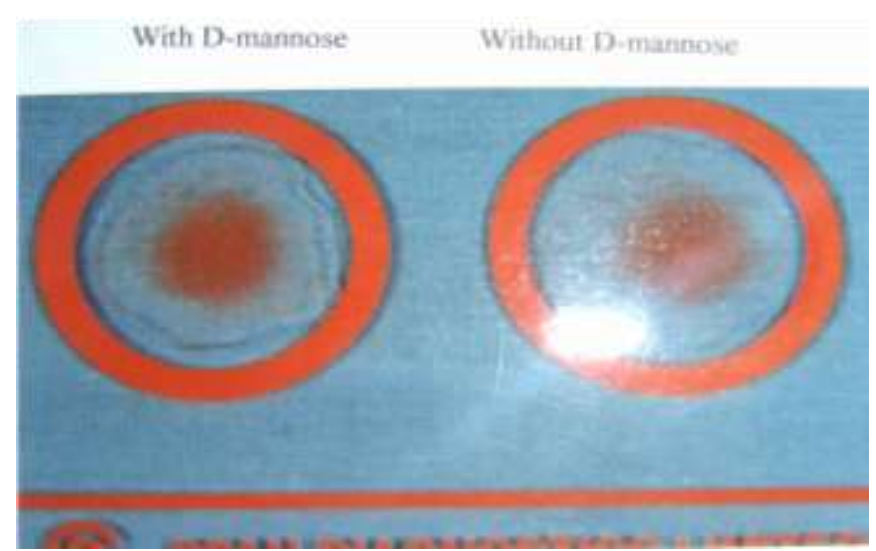

Fig. 1; showing mannose resistant haemagglutination

Table 1; heamagglutination pattern among haemolytic E.coli with and without mannose

\begin{tabular}{|lcccccc|}
\hline $\begin{array}{l}\text { Sr. No. } \\
\text { MSHA }\end{array}$ & Source & Total No. of Haemolytic Strains & MRHA & MSHA & MRHA, \\
\hline 1. & Urine & 181 & 87 & 15 & 79 \\
\hline 2. & Vaginal/Cervical swab & 10 & 3 & - & 7 \\
\hline 3. & Stool & 7 & 1 & - & 6 \\
\hline 4. & Pus \& Others & 7 & 4 & - & 3 \\
\hline & Total & $\mathbf{2 0 5}$ & $\mathbf{9 5}$ & $\mathbf{1 5}$ & $\mathbf{9 5}$ \\
\hline
\end{tabular}

Table 2; incidence of cell surface hydrophobicity among haemolytic E.coli

\begin{tabular}{|lccc|}
\hline Sr. No. & Source & Total Number of Haemolytic Strains & Positive - Number (\%) \\
\hline 1. & Urine & 181 & $125(69.06 \%)$ \\
\hline 2. & Vaginal/Cervical swab & 10 & $7(70 \%)$ \\
\hline 3. & Stool & 7 & $3(42.86 \%)$ \\
\hline 4. & Pus \& Others & 7 & $4(57.14 \%)$ \\
\hline & Total & $\mathbf{2 0 5}$ & $\mathbf{1 3 9}(\mathbf{6 7 . 8 0 \%})$ \\
\hline
\end{tabular}

\section{Discussion}

Apart from haemolysin, colicin, aerobactin production, serum bactericidal activity, the factors like adhesive property and cell surface hydrophobicity are also known to contribute to the virulence of E.coli $[7,12,13]$. The adherence properties were originally recognized in terms of haemagglutination of various erythrocytes and they correlate well with presence of fimbriae on bacterial surface [14]. Haemagglutination and cell surface hydrophobicity are indirect evidences of the presence of fimbriae on the bacterial cell. Two classes 
of fimbriae have been recognized on the surface of E.coli. Haemagglutination by common or Type 1 fimbriae termed as mannose sensitive (MS), inhibited by D-mannose, bind to mannose containing receptors [15]. The second heterogeneous class of fimbriae, produce mannose resistant (MR) haemagglutination, is not inhibited by D-mannose and bind to a variety of receptors present. Both MR and MSHA fimbriae are produced in vivo during Urinary Tract Infection (UTI) and cause E.coli to adhere to urinary tract epithelium, though MSHA fimbriae type I are non virulent determinants, colonize better than non-fimbriate strains. The role of MSHA fimbriae (Type I) in the pathogenesis of UTI remains controversial whereas the presence of MR fimbriae on E.coli correlates with virulence in clinical urinary tract infection [4,16-18]. The detection of fimbriae can be achieved by direct and indirect techniques. The direct method involves the use of either electron microscopy or antisera and uroepithelium adhesion assay.

On the other hand, the indirect methods are salt aggregation test and haemagglutination test. The indirect methods are simple, easy to perform and can be introduced in a routine laboratory. MRHA is an indirect evidence of presence of fimbriae [19]. A number of different MR fimbriae can be distinguished on the basis of specific receptor to which they bind. They are P, X, S, G, CFA I \& CFA II [20]. The best studied of these are P fimbriae that bind to antigens of $\mathrm{P}$ blood group system and P-receptors present in kidney and bladder [21-23].

In the present study, out of 2001 E.coli isolates, 205 (10.24\%) were haemolytic. Of the 205 haemolytic strains, a total of 110 strains exhibited haemagglutination indicating thereby the presence of fimbriae on their surface. Type I, MS and MR fimbriae were detected. Ninety five (86.36\%) and $15(13.6 \%)$ strains of total haemolytic E.coli showed MRHA and MSHA respectively. Whereas $46.34 \%$ strains exhibited no haemagglutination. From urine, the most frequently processed samples, $48.06 \%, 8.28 \%$ and $43.64 \%$ strains showed MRHA, MSHA and MRHA MSHA respectively. These findings are almost similar in line with another study, which reported MRHA, MSHA and MRHA MSHA in 43\%, 14\% and 43\% strains respectively [10]. Whereas other workers reported only $21 \%$ strains to be positive for MRHA among urinary isolates.

Amongst urinary haemolytic E.coli strains (181), MRHA adhesins were found in 48.06\% (87) and only $14.2 \%$ (1) strains possessed MRHA adhesins among fecal E.coli isolates. This is quite a higher incidence corresponds with other study whereas another study reported $13.5 \%, 1.2 \%$ strains to be positive for MRHA among urinary and fecal isolates respectively [24,25].

The haemolytic activity and MRHA property were more frequent among urinary strains than among fecal strains. Sunanda et al., (1999) reported 70\% and 56\% strains to be fimbriated E.coli from UTI cases and fecal strains respectively. The low incidence in our study may be because of very close group comprising of only haemolytic E.coli was considered for the study. Alternatively it may be due to the fact that only strains possessing fimbriae other than $\mathrm{P}$ were detected as we used only type A human erythrocyte for HAT.

Another indirect method to detect the presence and type of fimbriae on bacterial cell is by demonstrating cell surface hydrophobicity [26]. Bacteria aggregating in $\leq 1.4 \mathrm{M}$ ammonium sulphate solution have been considered to possess hydrophobic fimbriae. Type I fimbriae are strongly hydrophobic [27]. In the present study, 67.80\% (139) strains have been found to possess hydrophobic fimbriae. Seventy nine (38.53\%) strains were found to have both hydrophobic and haemagglutinating property. Out of these $53.3 \%$ strains were MSHA and hydrophobic indicating the presence of type I fimbriae, $33.17 \%$ strains were MRHA and hydrophobic. Amongst urinary haemolytic isolates (181), 69.06\%, $48.06 \%$ and $8.28 \%$ strains were found to be hydrophobic, MRHA and MSHA respectively. This incidence is quite higher as compared to fecal isolates i.e. $42.86 \%, 14.2 \%$ and $0 \%$ respectively. Whereas there was no significant difference in the incidence of cell surface hydrophobicity amongst haemolytic E.coli strains isolated from other sources viz. vaginal/ cervical swabs, pus and others i.e. $70 \%, 57.14 \%$ respectively. Other workers reported $52 \%$ and $81 \%$ strains to be hydrophobic amongst haemolytic E.coli [10,28].

\section{Conclusions}

It has been found that cell surface hydrophobicity is more sensitive method of detecting fimbriated strains as compared to haemagglutination test. On the contrary, haemagglutination method tells about haemagglutinating property (MRHA/ MSHA) of fimbriae, which is more specific in relation to adherence to uroepithelium in UTI cases. In our study, only $38.53 \%$ strains of haemolytic E.coli were found to be fimbriated by both methods. The haemolytic activity of E.coli is also found associated with fimbriated strains in urinary isolates. In the present study, $21.8 \%$ haemolytic strains were haemagglutinating as compared to other study, which reported $13.5 \%$ strains to have haemolytic activity [25]. Thus both haemolytic activity and presence of fimbriae act as virulence factors for pathogenesis of UTI.

\section{References}

[1] A.W. Bruce, R.C.Y. Chan, D. Pinkeron, A. Morales, and P. Chadwick, Adherence of gram negative uropathogens to human uroepithelial cell, J. Urol., 130, 1983, 293-298.

[2] A.J. Schaeffer, J.M. Jones, and J.K. Dunn, Association of in-vitro Escherichia coli adherence to vaginal and buccal epithelial cells with susceptibility of women to recurrent urinary tract infections, N. Eng. J. Med., 304, 1981, 1062-1066. 
[3] N.S. Sunanda, A.C. Chhaya, and A.A. Pathak, Virulence factors in uropathogenic E.coli, Indian J. Patho. Microbiol., 42(3), 1999, 321-325.

[4] A. Pere, and B. Nowicki, Expression of P, type I and type I C fimbriae on Escherichia coli in the urine of patients with acute urinary tract infection, J. Infect. Dis., 156, 1987, 567-574.

[5] K.L. Vosti, Relationship of hemagglutination to other biological properties of serologically classified isolates of Escherichia coli. Infect. Immune., 25, 1979, 507-512.

[6] S.H. Parry, and D.M. Rooke, Adhesins and colonization factors of E.coli, in M.Sussman (Ed.), The virulence of E.coli, (London: Academic Press Inc. Ltd., 1985) 79-155.

[7] S.J. Cavalieri, G.A. Bohach, and I.S. Snyder, Escherichia coli alpha-hemolysin: characteristics and probable role in pathogenicity, Microbial. Rev., 48, 1984, 326-343.

[8] J.G. Coolle, J.P. Dugvid, A.G. Fraser, B.P. Marmion, and A. Simmons, Mackie and McCartney practical medical microbiology, $14^{\text {th }}$ ed., (Churchill Livingstone,1996) 53.

[9] P.R. Edwards, and W.H. Ewing, Identification of entrobacteriaceae, $3^{\text {rd }}$ ed., (Minneapolis: Burgress publishing company, 1972 ) 290.

[10] L. Siegfried, M. Kmetova, H. Puzova, M. Malokacova, and J. Filka, Virulence associated factors in Escherichia coli strains isolated from children with urinary tract infections, J. Med. Microbiol., 4, 1994, 127-132.

[11] D.G. Evans, and J.D.J Evans, New surface associated heat labile colonization factor antigen (CFA/11) produced by entrotoxigenic E.coli, Infect. Immun., 21,1978, 638.

[12] L. Siegfried, H. Puzona, M. Kmetova, and A. Kerestesona, Killing of alpha hemolytic and non-hemolytic Escherichia coli strains in human serum and polymorphonuclear leucocytes, J. Med. Microbiol., 37, 1992, 3-7.

[13] S.L. Akulwar, A.M. Kurhade, and A.M. Saoji, Hemolytic Escherichia coli in etiopathogenesis of pylonephritis in rats - An experimental study, Ind. J. Pathol. Microbiol., 40, 1997, 47-49.

[14] J.P. Duguid, R.S. Anderson, and I. Compbell, Fimbriae and adhesive properties in Salmonellae J. Path. Bact., 92, 1966,107-108.

[15] N. Sharon, and I. Ofek, Mannose specific surface lectins. in D. Mirelman (Ed.), Microbial Lectins and Agglutinins: Properties and Biological Activities, (Willy, New York, 1986) 55-81.

[16] P. O'Hanley, Vaccine against Escherichia coli urinary tract infections, in G.C. Woodrow, M.M. Levine (Ed.), New Generation of Vaccine, (New York: Marcel Dekker, 1990) 631-648.

[17] P.V. Kiselius, and W.R. Schwan, In vivo expression and variation of Escherichia coli type I and P pili in the urine of adults with acute urinary tract infections, Infect. Immun., 57, 1989, 1656-1662.

[18] I. Ofek, A. Mosek, and N. Sharon, Mannose-specific adherence of Escherichia coli freshly excreted in the urine of patients with urinary tract infections and of isolates subcultured from infected urine, Infect. Immun., 34. 1981, 708-711.

[19] D.G. Evan, R. Silver, J.D.J. Evan, and S.L. Gorbach, Plasmid controlled colonization factor associated with virulence in E.coli entrotoxigenic for human. Inf. Immunity., 12, 1975, 656-667.

[20] D.G. Evan, L.D.J. Evan, and W. Tjoa, Hemagglutination of human group 'A' erythrocytes by enterotoxigenic E.coli isolated from adults with diarrhea, Infect. Immun., 18, 1977, 330-333.

[21] G. Kellenius, S.B. Svenson, R. Mallby, B. Cedergern, H. Hultberg, and J. Winberg, Structure of carbohydrate part of receptor on human uroepithelial cells for pylonephritic Escherichia coli, Lancet ii, 1986, 604-606.

[22] H. leffler, and C. Svanborg-Eden, Chemical identification of glycosphingolipid receptor for Escherichia coli attaching to human urinary tract epithelial cells and agglutinating human erythrocytes, FEMS., 8, 1980, 127-134.

[23] J.R. Johnson, Urinary tract infection, in M. Sussman (Ed.), Escherichia coli: Mechanism of virulence, (Cambridge: Cambridge University Press, 1997) 459-549.

[24] J. Hacker, M. Ott, G. Schmidt, R. Hull, and W. Goebel, Molecular staining of F8 fimbrial antigen from Escherichia coli, FEMS Microbiol. Lett., 36(2-3), 1986, 139-144.

[25] N. Karabiber, and S. Turet, Mannose-resistant haemagglutination (MRHA), type I fimbriae and haemolysin production of urinary and fecal Escherichia coli strains, Mikrobiyol Bul., 26(1), 1992, 12-16.

[26] M. Jayasheela, N. Kumari, R.K. Shandil, and S.N. Saxena, Characteristics of Escherichia coli isolates from infantile and childhood diarrhea, Indian J. Pediats., 56(1), 1989, 87-92.

[27] R. Steadman, and N. Topley, Cellular activation by uropathogencic Escherichia coli. Escherichia coli: Mechanism of virulence. in M. Sussman (Ed.), (Cambridge: Cambridge University Press, 1997) 553-578.

[28] P. Kour, M. Jayasheela, A. Chakraborty, and S.N. Saxena, Characteristic of Escherichia coli isolates from cases of significant bacteriuria, Ind. J. Med. Microbiol., 1991, 107-113. 